\title{
Surface characterization of sol-gel derived indium tin oxide films on glass
}

\author{
$P$ K BISWAS*, A DE, L K DUA and L CHKODA ${ }^{\dagger}$ \\ Sol-Gel Division, Central Glass and Ceramic Research Institute, Kolkata 700 032, India \\ ${ }^{\dagger}$ Experimentelle Physik II, Physikalisches Institut der Universitat Wurzburg, Am Hubland, 97074 Wurzburg, \\ Germany
}

MS received 15 February 2006; revised 12 April 2006

\begin{abstract}
Indium tin oxide (ITO) films containing different In : Sn atomic ratios, viz. 90 : $10,70: 30,50: 50$, $30: 70$, were deposited on two types of glass substrates by sol-gel spinning technique. XPS analysis of the films was done under as-received and after-sputtering conditions. The narrow spectra obtained for the Na1s, In $3 d$, Sn3d and O1s have been discussed. Oxygen was found to exist in three chemical environments in as-received samples due to the existence of (i) environmental hydroxyl (-OH) group, (ii) crystalline ITO and (iii) amorphous ITO; but it was in two chemical environments, (ii) and (iii), after surface cleaning by sputtering. The presence of both tin metal and tin oxides was confirmed by the peak analysis of Sn3d. The In : Sn atomic ratio taken in the precursor sols did not change considerably in the case of developed films of low Sn content, but considerable change was observed in the films having high Sn content.
\end{abstract}

Keywords. Indium tin oxide (ITO); sol-gel film; resistivity; XPS.

\section{Introduction}

Indium tin oxide (ITO) coating on glass is an important item in the field of optoelectronic devices such as solar cells (Barua and Banerjee 1992), electrochromic systems, lightemitting diodes, etc for its large band gap (Ohhata et al 1979; Balasubramanian and Subramanyam 1989) and special optical and electrical (Frank et al 1981; Kostlin 1982; Biswas et al 2000; Cho et al 2000; Kim et al 2001) properties. These properties are greatly influenced by oxygen stoichiometry and dopant concentration. Usually in ITO, maximum free carrier concentration is obtained with the dopant concentration, 5-10 at.\% Sn (Christian and Shatynski 1983; Naseem and Coutts 1986; Karasawa and Miyata 1993; Mori et al 2002). The crystalline bixbyite phase of $\operatorname{In}_{2} \mathrm{O}_{3}$ exists even in high concentration of Sn due to very high solid solubility of tin in $\operatorname{In}_{2} \mathrm{O}_{3}$ (Kostlin et al 1975). On the other hand, Parent et al (1992) reported that the ITO network is disordered at higher dopant concentration. Hence, it is noteworthy to carry out basic research on the bonding behaviour of different elements in ITO of relatively high dopant concentration. This knowledge can be gained by XPS study as the binding energy of the elements present in ITO would differ with change in environments. Extensive work (Kobayashi et al 1992; Ishida et al 1993; Mori et al 2002) on the study of surface characterization of PVD developed ITO films has been done for its wide use in thin

*Author for correspondence (pkbiswas@cgcri.res.in) film form, but the study on the above properties with wide variation of dopant concentration is scanty (Kulkarni and Knickerbocker 1992; Cao et al 1998). The present report focuses on surface characterization of ITO films deposited on soda lime silica (SLS) glass. As the sol-gel technique is cost effective and produces relatively homogeneous films (Arfsten et al 1984; Furusaki and Kodaira 1991; Takahashi et al 1992, 1997; Gallagher et al 1993; Cao et al 1998; Atashbar et al 1999), it can be utilized for the development of homogenous ITO films on glass of relatively large dimensions. Since the diffusion of $\mathrm{Na}^{+}$ion of SLS substrates occurs towards the deposited films during thermal curing, the electrical conductivity of ITO decreases resulting in decrease in efficiency of functional properties of ITO. If silica barrier layer be deposited on SLS substrate then it may inhibit the $\mathrm{Na}^{+}$ion diffusion in the film and the modified substrate can be used for ITO deposition. This work deals with surface characterization of sol-gel ITO films of relatively high dopant concentration, deposited on bare and silica barrier layer coated SLS glass substrates by XPS study.

\section{Experimental}

\subsection{Preparation of precursors}

2.1a ITO system: The starting materials of the precursor sols of ITO layer were hydrated stannic chloride $\left(\mathrm{SnCl}_{4} \cdot 5 \mathrm{H}_{2} \mathrm{O}\right.$, 98\% GR, Loba Chemie) and indium metal ingot (99.9\%, 
Sisco Research Laboratory) derived hydrated indium nitrate. Concentration of the sols was $6 \mathrm{wt} \%$ equivalent $\mathrm{In}_{2} \mathrm{O}_{3}-\mathrm{SnO}_{2}$ having $\mathrm{In}: \mathrm{Sn}$ atomic ratios of $90: 10,70: 30$, $50: 50$ and $30: 70$. The sol was prepared in two steps. First, required amount of indium nitrate solution was mixed with mixed solvent (1:1 by volume) of 1-propanol and 2methoxyethanol and then the required amount of acetic acid (E. Merck India Ltd. GR; In : acetic acid = 1:1) and acetyl acetone $(a c a c)($ SRL, GR; In : $a c a c=1: 1)$ were added to the above solution with stirring. The second step was to dissolve the required amount of $\mathrm{SnCl}_{4} \cdot 5 \mathrm{H}_{2} \mathrm{O}$ in the same mixed solvent which was added to the initial solution and stirred for $\sim 1 \mathrm{~h}$. The final solution was aged for $16 \mathrm{~h}$ for coating.

2.1b Silica system: Precursor sol of $6 \mathrm{wt} \%$ equivalent $\mathrm{SiO}_{2}$ prepared from tetraethylorthosilicate (TEOS) was used for the deposition of silica layer as barrier layer. The detailed preparative procedure of polymeric $\mathrm{SiO}_{2}$ precursor was given in our earlier paper (Kundu et al 1989).

\subsection{Deposition of thin films}

2.2a Cleaning of substrate: Soda lime silica glass (dimension, $5 \times 5 \mathrm{~cm}, 3 \mathrm{~mm}$ thickness) was cleaned (Atta et al 1990) following a number of steps. The glass substrates were first immersed in a solution of Extran pure (E. Merck India Ltd.) $(2.0 \mathrm{vol} \%)$ in water for $1 \mathrm{~h}$ and then treated ultrasonically for $40 \mathrm{~min}$. The substrates were then washed with distilled water several times. Ultrasonic treatment (for about $30 \mathrm{~min}$ ) in $0.01 \mathrm{M} \mathrm{HCl}$ or $\mathrm{HNO}_{3}$ medium was again followed. The substrates were then washed thoroughly with distilled water followed by washing with GR grade acetone (E. Merck India Ltd.), wiping carefully with Whatman lens cleaning tissue paper and subsequent air drying in a relatively dust-free room.

2.2b Silica films: Some of these cleaned substrates were used for the deposition of silica layer of around $200 \mathrm{~nm}$ thickness. Spinning technique (rate, 1200-1500 rpm) was followed for the deposition of sol layer. Next, the layer was heated at $450 \pm 5^{\circ} \mathrm{C}$ with a soaking time of $0.5 \mathrm{~h}$ to transform it to oxide layer.

2.2c ITO films: The salt (In- and Sn-) derived indium tin oxide (ITO) coatings of different $\mathrm{In}: \mathrm{Sn}$ atomic ratios $(90: 10,70: 30,50: 50$ and $30: 70)$ were deposited on two types of substrates: (i) soda lime silica glass (SLS), where the samples prepared from the corresponding precursors are designated as WS-1, WS-2, WS-3, WS-4 and (ii) $\sim 200 \mathrm{~nm}$ thick SLS glass where the samples prepared from the corresponding precursors are designated as S-1, S-2, S-3, S-4, respectively. The detailed preparative procedure is given elsewhere (Biswas et al 2000, 2003). The coatings were annealed at $500 \pm 5^{\circ} \mathrm{C}$ in $\mathrm{H}_{2} \mathrm{O}$ vapour atmo- sphere where carrier gas was nitrogen. The annealing time was about $30 \mathrm{~min}$. Indium tin oxide layers of about 100 $500 \mathrm{~nm}$ thicknesses containing different atomic ratios of In : Sn were prepared in this way. Single operation yielded a layer of $100-150 \mathrm{~nm}$ physical thickness. To increase physical thickness number of operations was increased; after each operation the samples were cured at $500 \pm 5^{\circ} \mathrm{C}$ in air with $30 \mathrm{~min}$ soaking. The curing was chosen at the above temperature as the softening point of soda lime silica (SLS) glass was $\sim 550^{\circ} \mathrm{C}$. Annealing in water vapour was carried out after attaining the requisite thickness. Only two operations were followed for bare SLS substrates while four operations were followed for silica barrier layer coated SLS substrate, because, for bare substrate there is a possibility of $\mathrm{Na}^{+}$ion diffusion into the film with increasing number of heating.

\subsection{Characterization}

The physical thickness of the films was measured by stylus method (Tencor's Alpha-Step 200). Crystallinity of the samples was examined with Siemens D5005 goniometer $\left(20-70^{\circ}, 0 \cdot 60^{\circ} / \mathrm{min}\right)$ using nickel filtered $\mathrm{CuK}_{\alpha}$ radiation. The electrical conductivity of the films were measured at room temperature following four-probe van der Pauw method. The X-ray photoelectronic spectroscopic (XPS) characterization was done by introducing the samples into an UHV chamber equipped with helium (He) discharge lamp for UPS, $\mathrm{MgK}_{\alpha}$ X-ray source for XPS, heating and $\mathrm{Ar}^{+}$sputtering cleaning facilities. The $\mathrm{Ar}^{+}$-sputtering was continued for $30 \mathrm{~min}$ maintaining a current density of 6$8 \mu \mathrm{A} \mathrm{cm}^{-2}$ with a kinetic energy of $1 \mathrm{keV}$. The base pressure of the chamber was $6.67 \times 10^{-8}$ Pascal. For the XPS analysis the energy resolution was $0.1 \mathrm{eV}$ for the $\mathrm{MgK}_{\alpha}$ line at $1253.6 \mathrm{eV}$. The XPS study of the samples was done under two conditions: (i) as-received and (ii) aftersputtering. The XPS spectra of the elements present in the film were fitted by Voigt fit-function with corresponding FWHM and linear background. The quantitative analyses were performed by using Hartree-Slater sensitivity factors of elements for integral peak intensity with reference to Briggs and Seah (1990) and Scofield (1976). During XPS experimentation, charging was not observed on the ITO samples.

\section{Results and discussion}

The thickness of ITO films deposited on bare SLS glass substrate (sample nos. WS-1 to WS-4) was in the range 260-320 nm ( $\pm 25 \mathrm{~nm})$, while that deposited on silica barrier layer coated SLS glass substrates (sample nos. S-1 to $\mathrm{S}-4)$ varied from $400( \pm 25 \mathrm{~nm})$ to $560 \mathrm{~nm}( \pm 25 \mathrm{~nm})$. Xray diffraction pattern of the deposited films shows (figure 1) broad background with relatively broad diffraction peaks indicating presence of amorphous nature along with 
Table 1. Sample designation, chosen In : $\mathrm{Sn}$ in the precursors, nature of substrate, electrical resistivity and the evaluated In : Sn of ITO film by XPS study.

\begin{tabular}{lcccc}
\hline $\begin{array}{l}\text { Sample } \\
\text { designation }\end{array}$ & $\begin{array}{c}\text { In:Sn in } \\
\text { precursor sol }\end{array}$ & $\begin{array}{c}\text { Nature of } \\
\text { substrate }\end{array}$ & $\begin{array}{c}\text { Resistivity } \\
(\text { ohm.cm })\left(\times 10^{-3}\right)\end{array}$ & $\begin{array}{c}\text { In: Sn } \\
\text { evaluated from XPS } \\
\text { (after sputtering) }\end{array}$ \\
\hline S-1 & $90: 10$ & $\begin{array}{c}\text { Silica coated soda } \\
\text { lime silica glass }\end{array}$ & $1 \cdot 5 \pm 0 \cdot 3$ & $88: 12$ \\
S-2 & $70: 30$ & -do- & $1 \cdot 4 \pm 0 \cdot 2$ & $87: 13$ \\
S-3 & $50: 50$ & -do- & $3 \cdot 5 \pm 0 \cdot 6$ & $52: 48$ \\
S-4 & $30: 70$ & -do- & $2700 \pm 500$ & $42: 58$ \\
WS-1 & $90: 10$ & Soda lime silica glass & $5 \cdot 0 \pm 0 \cdot 9$ & $92: 8$ \\
WS-2 & $70: 30$ & -do- & $2 \cdot 3 \pm 0 \cdot 4$ & $72: 28$ \\
WS-3 & $50: 50$ & -do- & $3 \cdot 9 \pm 0 \cdot 7$ & $71: 29$ \\
WS-4 & $30: 70$ & -do- & $410 \pm 70$ & $44: 56$ \\
\hline
\end{tabular}

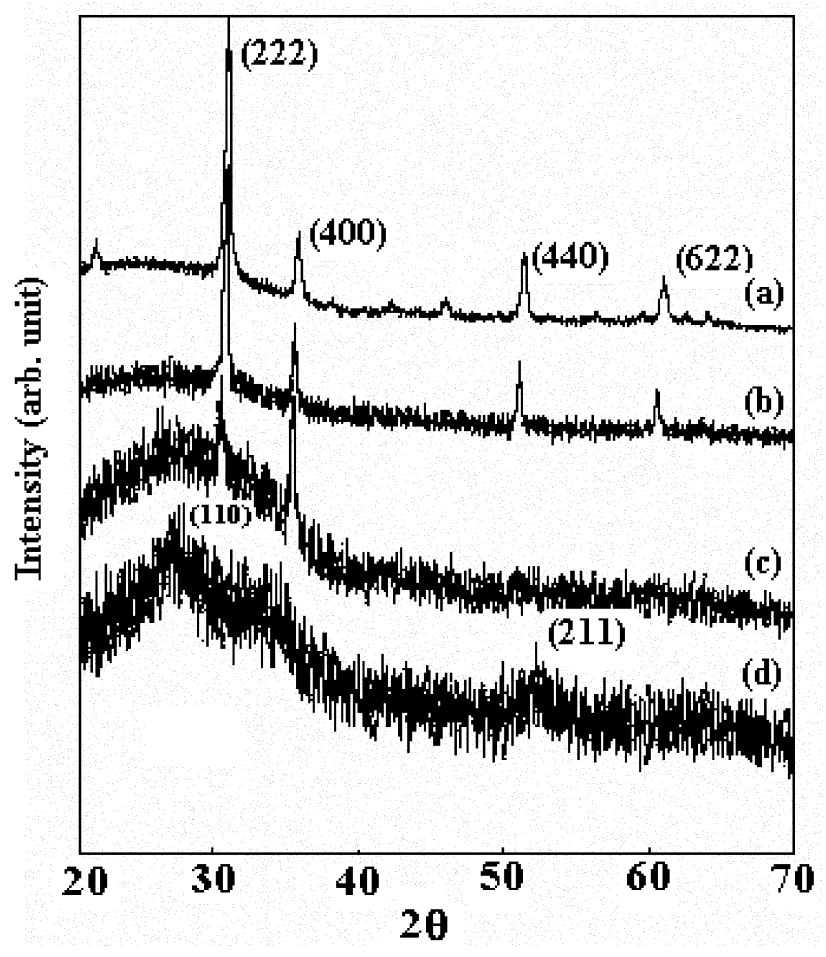

Figure 1. X-ray diffraction patterns of ITO films deposited on silica coated soda lime silica glass substrate from the precursor sols of different In : Sn ratios: (a) $90: 10$ (cubic $\mathrm{In}_{2} \mathrm{O}_{3}$ phase), (b) $70: 30$ (cubic $\mathrm{In}_{2} \mathrm{O}_{3}$ phase), (c) $50: 50$ (cubic $\mathrm{In}_{2} \mathrm{O}_{3}$ phase) and (d) $30: 70$ (cassiterite $\mathrm{SnO}_{2}$ phase).

some definite crystalline phases. Although we have observed cubic indium oxide phase even for the system of In : $\mathrm{Sn}=50: 50$, but it would be prudent to state the formation of a mixture of indium oxide and tin oxide and small amount of tin doped indium oxide has occurred as the content of tin is relatively high for the S-2 to S-4 and WS-2 to WS-4 samples. The films are electrically conducting and its resistivity $(\rho)$ (table 1 ) increases with increase in Sn concentration (> 30\%) possibly due to change in coordination numbers of In and $\mathrm{Sn}$ in ITO network. Resistivity of the S-1, S-2 and S-3 samples were relatively low with respect to those of the WS-1, WS-2, WS-3 samples and the variation of $\rho$ with change in substrate was not much. But there was a large variation in values of $\rho$ for S-4 and WS-4 samples although the $\mathrm{In}: \mathrm{Sn}$ ratio obtained from XPS study showed almost similar composition. Kostlin et al (1975) reported that there are Sn ions at close proximity to each other due to incorporation of higher $\%$ of tin. At this stage there is a large possibility of reduction of $\mathrm{Sn}$ (IV) to $\mathrm{Sn}(\mathrm{II})$ by the free electrons generated due to the creation of oxygen vacancy which occurs during the processing of ITO films under reducing condition. Hence, the $\mathrm{Sn}(\mathrm{IV})$ ions are associated with $\mathrm{Sn}(\mathrm{II})$ by an electrostatic force. This association forms a defect complex whose average electrical charge is $3^{+}$. Thus the associated $\mathrm{Sn}$ ions do not contribute to the electrical conduction (Kostlin et al 1975; Alam and Cameron 2002). In addition, Sn(II) or $\mathrm{Sn}(\mathrm{IV})$ forms interstitial bond with oxygen in ITO and exists as $\mathrm{SnO}$ or $\mathrm{SnO}_{2}$. Accordingly, it has a valency of $2+$ or $4+$ respectively. The lower valence state results in a net reduction in carrier concentration since a hole is created which acts as a trap and reduces conductivity. On the other hand, predominance of the $\mathrm{SnO}_{2}$ state means $\mathrm{Sn}^{4+}$ acts as an $n$-type donor releasing electrons to the conduction band.

If the above mechanism prevails in the film, then it may be presumed that the WS-4 sample has relatively high content of $\mathrm{SnO}_{2}$ and relatively less content of $\mathrm{SnO}$ assuming the concentration of the defect complex in WS-4 was same as in S-4. The relatively high content of $\mathrm{SnO}_{2}$ in WS-4 results in higher conductivity than that of S-4 sample.

The change in coordination number of In and $\mathrm{Sn}$ was also observed by EXAFS study of ITO with maximum $\mathrm{Sn}$ content, 39\% (Parent et al 1992). The knowledge of contribution of oxygen to In and Sn may be visualized by XPS experiments of the samples as the binding energy of oxygen will be different with change in environments such as crystalline or amorphous.

XPS experiments were carried out with the as-received samples as well as after cleaning the film surface by $\mathrm{Ar}^{+}$ sputtering and the obtained data were compared. The wide 
scan spectra (from 200-600 eV, not shown here) exhibit the peaks at $\sim 530 \cdot 0,493 \cdot 0,486 \cdot 0,452 \cdot 0,444 \cdot 0$ and $285 \cdot 0 \mathrm{eV}$ for $\mathrm{O} 1 s, \operatorname{Sn} 3 d_{3 / 2}, \operatorname{Sn} 3 d_{5 / 2}, \operatorname{In} 3 d_{3 / 2}, \operatorname{In} 3 d_{5 / 2}$ and $\mathrm{C} 1 s$, respectively. In addition, the XPS spectra from 1050-1150 eV (not shown here) exhibit peak at $\sim 1078 \mathrm{eV}$ due to Na1s. Composition of ITO layer for a specific sample was determined from the area intensities of the XPS peaks appearing for different elements. It was observed that the atomic ratios of $\mathrm{In}: \mathrm{Sn}$ of the films obtained by this analysis differed (table 1) in some cases from those taken in the precursors.

The XPS peaks in the regions of $\mathrm{O} 1 s$ measured at two different conditions exhibit the existence of oxygen in different environments in ITO. Under as-received condition the peaks at around 530.5 eV, 531.5 eV and 532.5 eV for $\mathrm{O} 1 \mathrm{~s}$ suggested the existence of three different environments while the peak at $532.5 \mathrm{eV}$ disappeared when the surface was cleaned (figure 2, table 2). The peak at $\sim 532.5 \mathrm{eV}$ may be attributed due to the oxygen of free hydroxyl groups which were etched out by sputtering. The existence of this oxygen is possibly due to environmental moisture trapped in the film surface. In addition, contamination of carbon from environment cannot be ruled out. As hydrogen atoms have higher electronegativity than indium atoms, oxygen atoms in the $\mathrm{In}-\mathrm{O}-\mathrm{H}$ species are less negatively charged than those in indium oxide where oxygen atoms are bound to six indium atoms. This implies that $\mathrm{O} 1 s$ binding energy in $\mathrm{In}-\mathrm{OH}$ species is higher than that in indium oxide (Ishida et al 1993). The removal of the above peak at around $532.5 \mathrm{eV}$ after $\mathrm{Ar}^{+}$ ion etching implies low density of the films. This is also evident from the remarkable change of $\mathrm{O}_{\text {tot }} / \mathrm{In}$ ratio after sputtering (table 3 ). The peak at around $530.5 \mathrm{eV}$ may be assigned as due to lattice oxygen in lattice crystal (Ishida et al 1993) and the other peak at around $531.5 \mathrm{eV}$ may be due to the oxygen atoms in an amorphous ITO phase. Thus, it can be inferred that the films contain both crystalline and amorphous phases. Fan and Goodenough (1977) also suggested that the peak, $\sim 531.5 \mathrm{eV}$, might be due to $\mathrm{O}^{2-}$ in an oxygen deficient region. In most of the cases the ratio of intensity of $\sim 530.5 \mathrm{eV}$ to $\sim 531.5 \mathrm{eV}$ peaks after sputtering condition was relatively high (table 2) with respect to that under as-received condition. This may be due to the condensation of two -OH groups of two In$\mathrm{OH}$ entities producing relatively high crystalline environment in ITO.

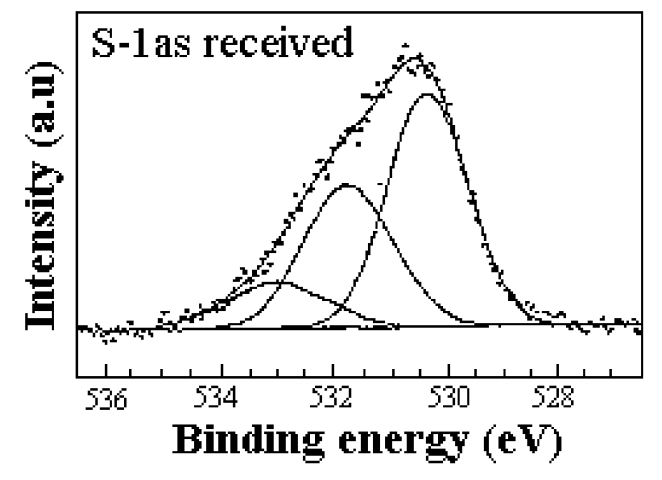

(a)

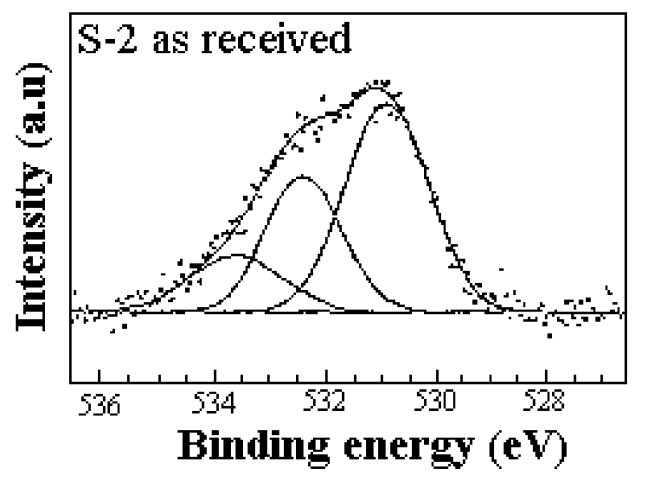

(c)

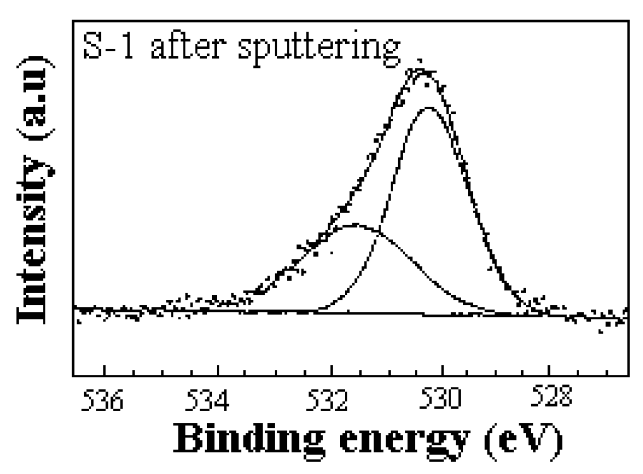

(b)

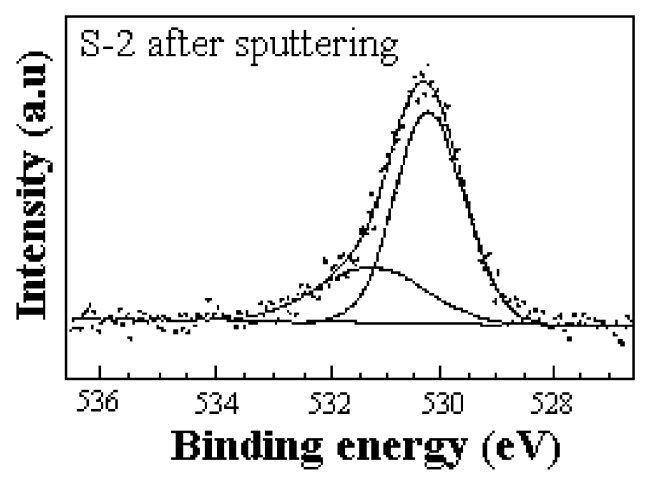

(d)

Figure 2. Results of peak analysis of O1s narrow XPS spectra measured in two conditions before (asreceived) and after sputter (cleaned) treatment (a), (b) for $\mathrm{S}-1$ (In:Sn $=90: 10)$ and (c), (d) for S-2 (In : Sn $=70: 30)$ samples. The original spectra (points) and fitting curves (lines) are shown. 
Table 2. The XPS peaks of O1s due to its existence in different environments in ITO films, their full widths at half-maximum (FWHM) and the intensity ratio of oxygens present in crystalline $(\sim 530 \cdot 5 \mathrm{eV})$ and amorphous $(531.5 \mathrm{eV})$ states.

\begin{tabular}{|c|c|c|c|c|}
\hline \multirow[b]{3}{*}{ Sample no. } & \multicolumn{4}{|c|}{ Experimental condition } \\
\hline & \multicolumn{2}{|c|}{ As-received } & \multicolumn{2}{|c|}{ After sputtering } \\
\hline & $\begin{array}{l}\text { Peak value }(\mathrm{eV}) \\
\text { (relative peak intensity) }\end{array}$ & $\begin{array}{l}\text { FWHM } \\
(\mathrm{eV})\end{array}$ & $\begin{array}{l}\text { Peak value }(\mathrm{eV}) \\
\text { (relative peak intensity) }\end{array}$ & $\begin{array}{l}\text { FWHM } \\
(\mathrm{eV})\end{array}$ \\
\hline \multirow[t]{4}{*}{ S-1 } & $530 \cdot 31$ & $1 \cdot 67$ & $530 \cdot 17$ & 1.63 \\
\hline & $531 \cdot 70$ & 1.90 & 531.43 & $2 \cdot 61$ \\
\hline & $(1 \cdot 7: 1 \cdot 0)$ & & $(2 \cdot 0: 1 \cdot 0)$ & \\
\hline & $532 \cdot 90$ & $2 \cdot 32$ & & \\
\hline \multirow[t]{4}{*}{ S-2 } & $530 \cdot 83$ & $1 \cdot 76$ & $530 \cdot 21$ & $1 \cdot 51$ \\
\hline & $532 \cdot 42$ & $1 \cdot 75$ & $531 \cdot 54$ & $2 \cdot 03$ \\
\hline & $(1 \cdot 4: 1 \cdot 0)$ & & $(1 \cdot 4: 1 \cdot 0)$ & \\
\hline & $533 \cdot 89$ & $1 \cdot 57$ & & \\
\hline \multirow[t]{4}{*}{ S-3 } & $530 \cdot 14$ & $1 \cdot 55$ & $530 \cdot 18$ & 1.46 \\
\hline & $531 \cdot 00$ & $1 \cdot 72$ & $530 \cdot 79$ & $2 \cdot 56$ \\
\hline & $(3 \cdot 2: 1 \cdot 0)$ & & $(4 \cdot 6: 1 \cdot 0)$ & \\
\hline & $532 \cdot 18$ & $2 \cdot 55$ & & \\
\hline \multirow[t]{4}{*}{ S-4 } & $530 \cdot 51$ & 1.69 & $530 \cdot 22$ & 1.41 \\
\hline & $531 \cdot 96$ & $1 \cdot 49$ & $530 \cdot 91$ & $2 \cdot 67$ \\
\hline & $(2 \cdot 7: 1 \cdot 0)$ & & $(2 \cdot 2: 1 \cdot 0)$ & \\
\hline & $533 \cdot 04$ & 1.93 & & \\
\hline \multirow[t]{4}{*}{ WS-1 } & $530 \cdot 23$ & $1 \cdot 52$ & $530 \cdot 30$ & $1 \cdot 50$ \\
\hline & $531 \cdot 27$ & $1 \cdot 67$ & $531 \cdot 50$ & $2 \cdot 10$ \\
\hline & $(3 \cdot 1: 1 \cdot 0)$ & & $(3 \cdot 7: 1 \cdot 0)$ & \\
\hline & $532 \cdot 13$ & $2 \cdot 31$ & & \\
\hline \multirow[t]{4}{*}{ WS-2 } & $530 \cdot 27$ & $1 \cdot 61$ & $530 \cdot 11$ & $1 \cdot 51$ \\
\hline & $531 \cdot 80$ & $1 \cdot 81$ & 531.45 & $1 \cdot 80$ \\
\hline & $(2 \cdot 6: 1 \cdot 0)$ & & $(5 \cdot 6: 1 \cdot 0)$ & \\
\hline & $533 \cdot 37$ & $2 \cdot 02$ & & \\
\hline \multirow[t]{3}{*}{ WS-3 } & - & - & $530 \cdot 21$ & $1 \cdot 37$ \\
\hline & & & $530 \cdot 74$ & $2 \cdot 59$ \\
\hline & & & $(2 \cdot 1: 1 \cdot 0)$ & \\
\hline \multirow[t]{4}{*}{ WS-4 } & $530 \cdot 33$ & $1 \cdot 61$ & $530 \cdot 21$ & 1.40 \\
\hline & $531 \cdot 52$ & $2 \cdot 10$ & $530 \cdot 63$ & $2 \cdot 28$ \\
\hline & $(1 \cdot 0: 3 \cdot 2)$ & & $(3 \cdot 6: 1 \cdot 0)$ & \\
\hline & $532 \cdot 21$ & $2 \cdot 93$ & & \\
\hline
\end{tabular}

Table 3. Ratios of oxygen (O) to indium (In) at different environments of oxygen present in ITO layers determined from the area intensities of XPS spectra in the regions of $\mathrm{O} 1 s$ and $\mathrm{In} 3 d$.

\begin{tabular}{|c|c|c|c|c|}
\hline \multirow[b]{2}{*}{ Sample no. } & \multirow[b]{2}{*}{$\mathrm{O}_{\text {tot }} /$ In (calc.) } & \multicolumn{3}{|c|}{ After-sputtering condition } \\
\hline & & $\mathrm{O}_{\sim 530.5} / \mathrm{In}(\%)$ & $\mathrm{O}_{\sim 531.5} / \mathrm{In}(\%)$ & $\mathrm{O}_{\text {tot }} / \mathrm{In}$ \\
\hline S-1 & $1 \cdot 71$ & $\begin{array}{l}1.00 \\
(56)\end{array}$ & $\begin{array}{l}0 \cdot 78 \\
(44)\end{array}$ & $1 \cdot 78$ \\
\hline S-2 & $2 \cdot 32$ & $\begin{array}{l}1.63 \\
(78)\end{array}$ & $\begin{array}{l}0.45 \\
(22)\end{array}$ & $2 \cdot 08$ \\
\hline S-3 & $3 \cdot 44$ & $\begin{array}{l}1 \cdot 28 \\
(54)\end{array}$ & $\begin{array}{l}1 \cdot 10 \\
(46)\end{array}$ & $2 \cdot 38$ \\
\hline S-4 & $6 \cdot 02$ & $\begin{array}{l}1 \cdot 71 \\
(71)\end{array}$ & $\begin{array}{l}0 \cdot 70 \\
(29)\end{array}$ & $2 \cdot 41$ \\
\hline WS-1 & $1 \cdot 71$ & $\begin{array}{l}1.03 \\
(86)\end{array}$ & $\begin{array}{l}0.39 \\
(14)\end{array}$ & 1.42 \\
\hline WS-2 & $2 \cdot 32$ & $\begin{array}{l}1.22 \\
(81)\end{array}$ & $\begin{array}{l}0.29 \\
(19)\end{array}$ & $1 \cdot 51$ \\
\hline WS-3 & $3 \cdot 44$ & $\begin{array}{l}0.83 \\
(53)\end{array}$ & $\begin{array}{l}0.73 \\
(47)\end{array}$ & $1 \cdot 56$ \\
\hline WS-4 & $6 \cdot 02$ & $\begin{array}{l}1.83 \\
(69)\end{array}$ & $\begin{array}{l}0 \cdot 83 \\
(31)\end{array}$ & $2 \cdot 66$ \\
\hline
\end{tabular}




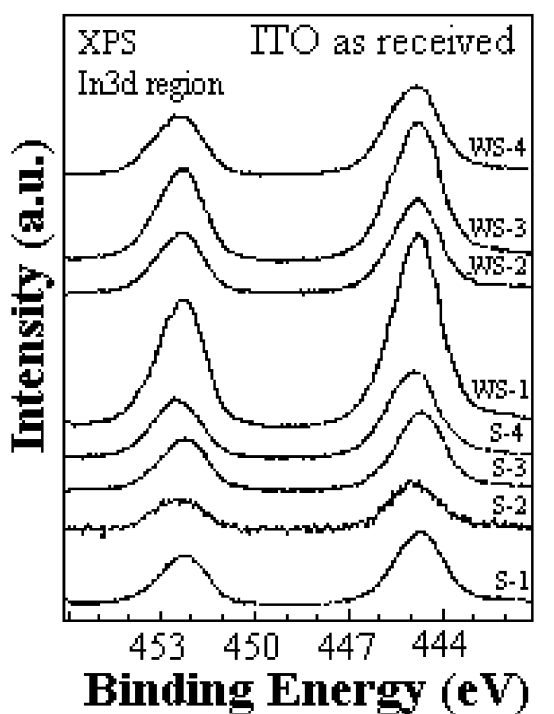

(a)

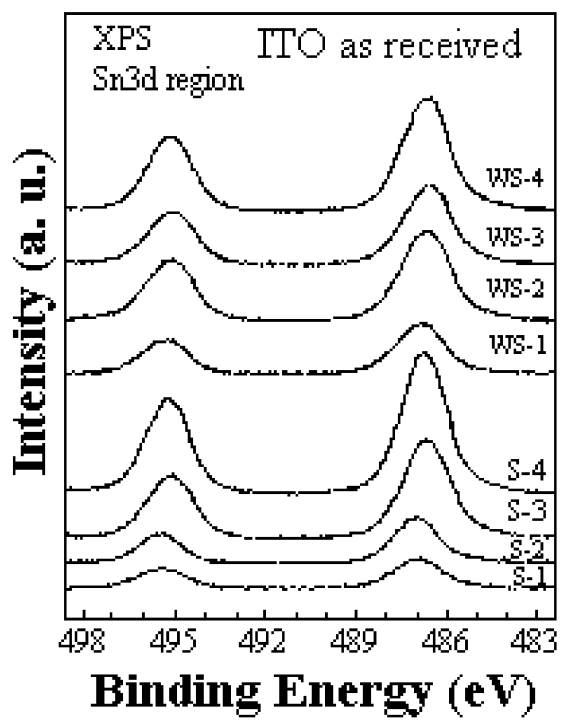

(c)

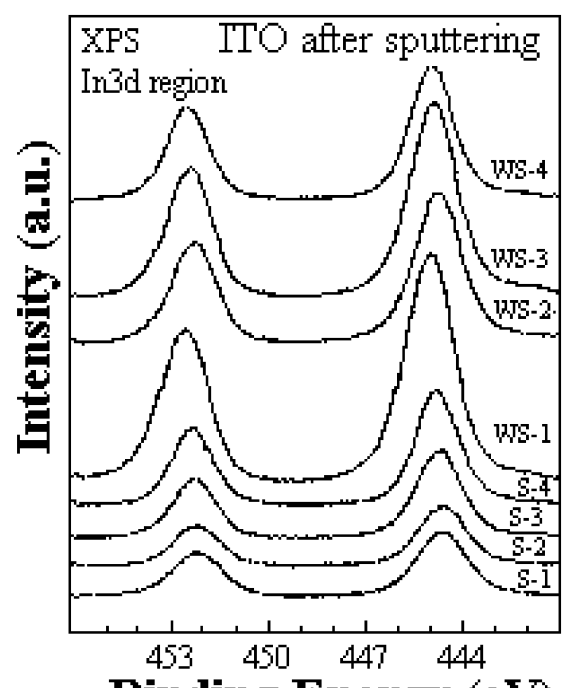

Binding Energy (eV)

(b)

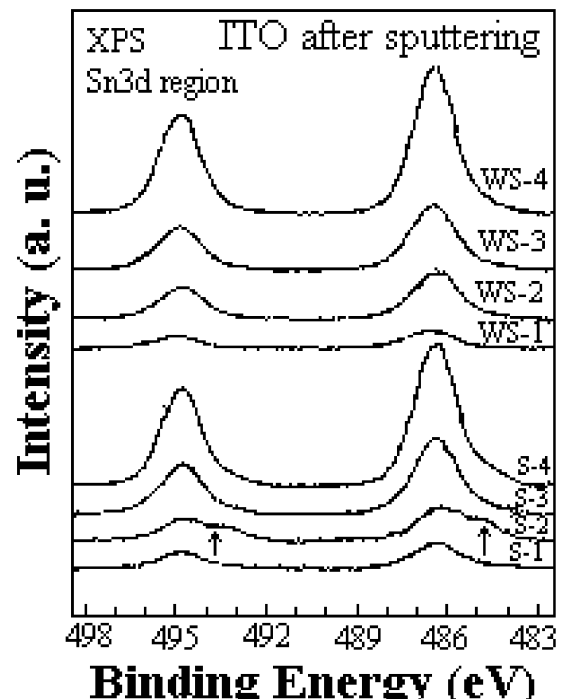

(d)

Figure 3. In $3 d$ and Sn $3 d$ XPS narrow spectra of all samples before (a), (c) and after (b), (d) sputtering; the arrows at $493.13 \mathrm{eV}$ and $484.71 \mathrm{eV}$ indicate the peak position for $\mathrm{BE}$ of $\mathrm{Sn} 3 d_{3 / 2}$ and $\mathrm{Sn} 3 d_{5 / 2}$, respectively due to $\mathrm{SnO} / \mathrm{Sn}$.

In the case of as-received samples (S-1 and S-2) deposited on barrier silica layer the binding energy (BE) for O1s of amorphous and crystalline states of ITOs has been increased by 0.72 and $0.52 \mathrm{eV}$, respectively with increase of Sn content from 10-30\%. This positive shift of BE implies substitution of In atom by $\mathrm{Sn}$ in $\mathrm{In}_{2} \mathrm{O}_{3}$ network resulting in In-O-Sn linkage. The increment in $\mathrm{BE}$ is due to more covalent character of $\mathrm{Sn}-\mathrm{O}$ bond because of relatively high polarization effect in $\mathrm{Sn}-\mathrm{O}$ bond than in $\mathrm{In}-\mathrm{O}$ bond. The higher polarization of $\mathrm{Sn}-\mathrm{O}$ is caused by higher charge density in $\mathrm{Sn}^{4+}$. With further increase in $\mathrm{Sn}$ content $(50 \%$, S-3), the corresponding BE decreased by $1.42 \mathrm{eV}$ and $0.69 \mathrm{eV}$ in the amorphous and crystalline states, respectively; this behaviour may be caused by the non-formation of In-O-
Sn linkage favouring formation of mixed oxides of $\mathrm{In}_{2} \mathrm{O}_{3}$ and $\mathrm{SnO}_{2}$. On further increase in $\mathrm{Sn}$ content $(70 \%)$, only initial behaviour was observed although casseterite $\mathrm{SnO}_{2}$ phase with more amorphous nature was the main crystalline phase. On the contrary, crystalline state remains constant even up to $70 \% \mathrm{Sn}$ of ITO on bare glass. The trend of nonformation of In-O-Sn linkage is present in the WS sample of $>30 \% \mathrm{Sn}$. In the case of cleaned surface, the crystalline state was constant even up to $70 \%$ Sn indicating In-O-Sn linkage was fixed. On the other hand, the linkage deteriorates in the case of amorphous state with increasing tin content as evident from the negative shift $(0.63-0.75 \mathrm{eV})$ of binding energy for $\mathrm{O} 1 s$. Similar behaviour was obtained for ITO films coated on bare substrate. 


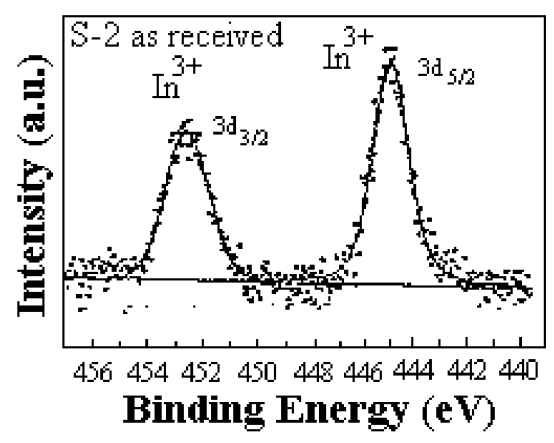

(a)

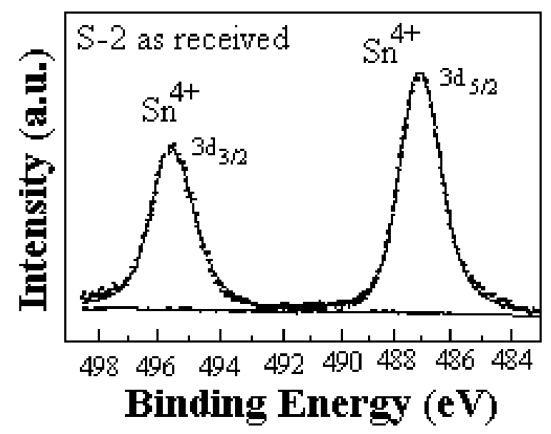

(c)

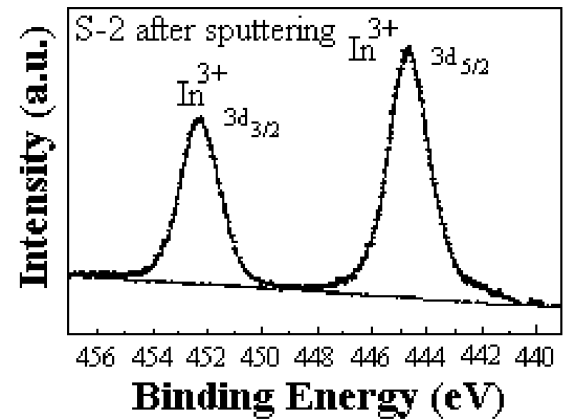

(b)

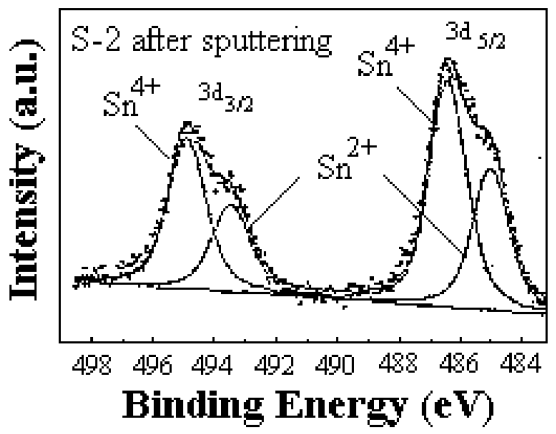

(d)

Figure 4. Peak fitting results of In $3 d$ and Sn3d narrow XPS spectra of S-2 (In : Sn = $70: 30$ ) sample before (a), (c) and after (b), (d) sputter treatment. After sputtering two $\mathrm{Sn} 3 d$ doublets for $\mathrm{Sn}^{4+}$ and metal $\mathrm{Sn} / \mathrm{Sn}^{2+}$ species are resolved.

Table 3 shows the ratios of the amount of total oxygen to that of indium in ITO films along with the contribution of oxygen to indium at different environments. These ratios were determined from the area intensities of the $\operatorname{In} 3 d_{5 / 2}$ and $\mathrm{O} 1 s$ peaks. The $\mathrm{O}_{\text {tot }} / \mathrm{In}$ ratio maintains tentatively the increasing order as followed in the case of precursor sols.

Figures $3 a$ and $b$ show XPS spectra of ITO films in the In $3 d$ region measured under as-received and after-sputtering conditions, respectively. In each case, the intensities of WS-1-WS-4 samples were relatively high with respect to those of S-1-S-4 samples. Two peaks were observed at $\sim 452 \mathrm{eV}$ and $\sim 444 \mathrm{eV}$ due to $\operatorname{In} 3 d_{3 / 2}$ and $\operatorname{In} 3 d_{5 / 2}$, respectively with respective FWHM being in the range 1.54$1.91 \mathrm{eV}$ and $1.54-1.93 \mathrm{eV}$. In the case of bare glass substrate, the peak intensity due to $\operatorname{In} 3 d$ decreased with decrease in In content, but the opposite effect was observed in S-1-S-4 samples.

Figures $3 c$ and d show XPS spectra in the $S n 3 d$ region for ITO films recorded at two conditions with almost similar spectral feature. Two peaks were observed at $\sim 495 \mathrm{eV}$ and $\sim 486 \mathrm{eV}$ due to $\mathrm{Sn} 3 d_{3 / 2}$ and $\mathrm{Sn} 3 d_{5 / 2}$, respectively. Intensity of the peaks increased with increase in Sn content. In this case, deposition of barrier layer (S-1-S-4) did not change the peak intensities significantly but an inflexion was observed for $\mathrm{Sn} 3 d_{5 / 2}$ in $\mathrm{S}-2$ sample after sputtering.

Figures $4 \mathrm{a}$ and $\mathrm{b}$ show typical well resolved XPS spectra of indium in the In $3 d$ region recorded under as-received and sputtering conditions. The $\operatorname{In} 3 d_{3 / 2}$ and $\operatorname{In} 3 d_{5 / 2}$ were observed at $452.47 \mathrm{eV}$ and $444.91 \mathrm{eV}$ with FWHM of $1.83 \mathrm{eV}$ and $1.78 \mathrm{eV}$, respectively under as-received condition. These values were close to that $(2 \cdot 0 \mathrm{eV})$ of vacuum evaporated ITO (Fan and Goodenough 1977) of In : Sn = 95:05. After sputtering, the peaks for the two $d$-states appeared almost in the same positions with separation of energies remaining almost constant. But, FWHM decreased from 1.83 to $1.54 \mathrm{eV}$ for In $3 d_{3 / 2}$ and from 1.78 to $1.54 \mathrm{eV}$ for In $3 d_{5 / 2}$ with increasing Sn contents (not shown here).

Figures $4 \mathrm{c}$ and $\mathrm{d}$ show typical well resolved XPS spectra of tin in the $\mathrm{Sn} 3 d$ region recorded under as-received and sputtering conditions. The peak analysis of typical S-2 sample exhibited $\mathrm{Sn} 3 d_{3 / 2}$ and $\mathrm{Sn} 3 d_{5 / 2}$ of $\mathrm{Sn}^{4+}$ in $\mathrm{SnO}_{2}$ at $494.70 \mathrm{eV}$ and $486.24 \mathrm{eV}$, respectively along with two additional peaks at $493.13 \mathrm{eV}$ and $484.71 \mathrm{eV}$. These two additional peaks are due to the presence of $\mathrm{Sn}$ metal or $\mathrm{Sn}^{2+}$ (Ishida et al 1993; Yamaguchi et al 2004; Pujilaksono et al 2005) as reduction of $\mathrm{Sn}^{4+}$ by sputtering is not unlikely as oxygen may be removed from the surface during $\mathrm{Ar}^{+}$sputtering. Their full widths at half-maximum (FWHM) also suggest the existence of $\mathrm{Sn}$ metal or $\mathrm{Sn}^{2+}$ of $\mathrm{SnO}$ in the films. For the other films (S-1, S-3, S-4, WS-1, WS-2, WS-3 and WS-4), its existence could not be resolved.

The diffusion character of sodium ion from the bare as well as from the barrier layer (silica) coated soda lime 
silica glass substrate was also analysed by XPS. Sodium content in the modified substrate decreased by the application of silica layer on SLS substrate as evident from the peak analysis due to $\mathrm{Na} 1 s(\mathrm{BE}, \sim 1078 \mathrm{eV})$ in the typical sample, WS-1 (Na, 4\%) and S-1 (Na, 3\%). This implies that the application of barrier layer of $200 \mathrm{~nm}$ thickness could not inhibit the diffusion of sodium ion into the film significantly. However, the barrier layer inhibited the diffusion of $\mathrm{Na}^{+}$in ITO to some extent as evident from the decrease in electrical resistivity of ITO coatings (table 1) having cubic crystalline phase.

\section{Conclusions}

Indium tin oxide (ITO) films with wide variation of $\mathrm{Sn}$ content $(10 \%, 30 \%, 50 \%$ and $70 \%)$ were deposited on bare as well as on barrier layer $\left(\mathrm{SiO}_{2}\right)$ coated soda lime silica glass, and XPS studies of the films were done to understand the behaviour of $\mathrm{In}-\mathrm{O}-\mathrm{Sn}$ linkage in amorphous and crystalline states. Oxygen was found to exist in three chemical environments under as-received condition while it was in two chemical environments in the case of aftersputtering condition. With increasing Sn content (>30\%), the In-O-Sn linkage is not favoured resulting in the disordered nature of the species. The FWHM of In $3 d_{3 / 2}$ and In $3 d_{5 / 2}$ were relatively less with respect to those values usually observed for $\mathrm{In}: \mathrm{Sn}=95: 05$. This discrepancy is possibly due to the large variation of Sn content in the film. For a specific chosen composition, In $: \mathrm{Sn}=70: 30, \mathrm{Sn}$ metal/ $\mathrm{SnO}$ was found to exist along with $\mathrm{SnO}_{2}$ if the films are sputtered. Application of ITO on silica barrier layer shows relatively low electrical resistivity due to inhibition of $\mathrm{Na}^{+}$ion diffusion but this was not visualized by XPS study possibly due to low thickness of silica layer (around $200 \mathrm{~nm}$ ).

\section{Acknowledgements}

Dr H S Maiti, Director, Central Glass \& Ceramic Research Institute, Kolkata, is deeply acknowledged for giving his constant encouragement to carry out the work. The Council of Scientific and Industrial Research (CSIR), India and DAAD, Germany, are also acknowledged for their financial assistance. Sincere thanks are also due to Prof. J Fricke and Dr M Sokolowski, Physikalisches Institut der Universitat, Wurzburg, for their constant cooperation in XPS analysis. They are also grateful to Mr U Gbureck and Dr J Probst, Experimentelle Zahnmedizin, Wurzburg University, for carrying out X-ray diffraction experiments. Thanks are also due to Bavarian Centre for Applied Energy Research (ZAE Bayern), Germany, for sponsoring an IndoGerman collaborative project under which detailed XPS analysis has been done. One of the authors (AD) is also indebted to ZAE Bayern, for providing him a fellowship to continue the work.

\section{References}

Alam M J and Cameron D C 2002 Thin Solid Films 420-421 76

Arfsten N J, Kaufmann R and Dislich H 1984 Ultrastructure processing of ceramics, glasses and composites (eds) L L Hench and D R Ulrich (New York: John Wiley \& Sons) p. 189

Atashbar M Z, Gong B, Sun H T, Wlodarski W and Lamb R 1999 Thin Solid Films 354222

Atta A K, Biswas P K and Ganguli D 1990 J. Non-Cryst. Solids 125202

Balasubramanian N and Subramanyam A 1989 J. Phys. D: Appl. Phys. 22206

Barua A K and Banerjee R 1992 New materials (eds) S K Joshi et al (New Delhi: Narosa Publishing House) p. 96

Biswas P K et al 2000 Photonics-2000 (eds) S K Lahiri et al (New Delhi: Allied Publishers Limited) 2 p. 636

Biswas P K, De A, Pramanik N C, Chakraborty P K, Ortner K, Hock V and Korder S 2003 Mater. Lett. 572326

Briggs D and Seah M P 1990 Practical surface analysis (New York: John Wiley \& Sons) 1

Cao X, Cao L, Yao W and Ye X 1998 Thin Solid Films 317443

Cho J-S, Koh S-K and Yoon K H 2000 J. Electrochem. Soc. 1471065

Christian K D J and Shatynski S R 1983 Thin Solid Films 108 319

Fan J C C and Goodenough J B 1977 J. Appl. Phys. 483524

Frank G, Kauer E and Kostlin H 1981 Thin Solid Films 77107

Furusaki T and Kodaira K 1991 High performance ceramic films and coatings (ed.) $\mathrm{P}$ Vincenzini (Amsterdam: Elsevier Science Publishers) p. 241

Gallagher D, Scanlan F, Houriet R, Mathieu H J and Ring T A 1993 J. Mater. Res. 83135

Ishida T, Kobayashi H and Nakato Y 1993 J. Appl. Phys. 73 4344

Karasawa T and Miyata Y 1993 Thin Solid Films 223135

Kim H, Horwitz J S, Kushto G P, Qadri S B, Kafafi Z H and Chrisey D B 2001 Appl. Phys. Lett. 781050

Kobayashi H, Ishida T, Nakamura K, Nakato Y and Tsubomura H 1992 J. Appl. Phys. 725288

Kostlin H 1982 Festkorperprobleme XXII 229

Kostlin H, Jost R and Lems W 1975 Phys. Status Solidi A29 87

Kulkarni A K and Knickerbocker S A 1992 Thin Solid Films 220321

Kundu D, Biswas P K and Ganguli D 1989 J. Non-Cryst. Solids 11016

Mori N, Ooki S, Masubuchi N, Tanaka A, Kogoma M and Ito T 2002 Thin Solid Films 4116

Naseem S and Coutts T J 1986 Thin Solid Films 13865

Ohhata Y, Shinoki I and Yoshida S 1979 Thin Solid Films 59 255

Parent Ph, Dexpert H and Tourillon G 1992 J. Electrochem. Soc. 139276,282

Pujilaksono B, Klement U, Nyborg L, Jelvestam U, Hill S and Burgard D 2005 Mater. Charact. 541

Scofield J H 1976 J. Electron Spectrosc. \& Rel. Phenom. 8129

Takahashi Y, Hayashi H and Ohya Y 1992 Mater. Res. Soc. Symp. Proc. 271401

Takahashi Y, Okada S, Tahar R B H, Nakano K, Ban T and Ohya Y 1997 J. Non-Cryst. Solids 218129

Yamaguchi M, Ektessabi A I, Nomura H and Yasui N 2004 Thin Solid Films 447-448 115 